\title{
Experimental Study on Performance of Gap Graded Concrete using Partial Replacement of Titanium Dioxide and Msand
}

\author{
Angel Benish M1, Uma Nambi J² \\ 1PG student, ${ }^{2} \mathrm{Head}$ of the Department \\ 1,2Civil Engineering Department, Paavai Engineering College, Namakkal, Tamil Nadu, India
}

\begin{abstract}
This paper reports an experimental investigation on the development of Gap graded concrete providing the optimal combination of strength and water permeability using $\mathrm{M}$ sand and admixtures. In this study, the Gap graded concrete is obtained by removing the fine aggregate wholly $(0 \%), 5 \%, 10 \%$ and $15 \%$ of replacing coarse aggregate with $M$ sand. The titanium dioxide is used as partial replacement to cement to study its behavior on mechanical properties of Gap graded concrete. Gap graded concrete trial mixes with different size of aggregate, with and without fine aggregates. Tested for its mechanical properties such as compressive strength, water permeability, and porosity. Gap graded concrete is a porous concrete which allows water and air to pass through it. The Gap graded concrete specimen of cube size of $150 \mathrm{~mm} \times 150 \mathrm{~mm} x$ $150 \mathrm{~mm}$ and they were cured in water for the period of 7,14, 28 days. The compressive strength test and permeability is done in laboratory after curing. Then the compressive strength of Gap graded concrete is compared to the compressive strength of M20grade of concrete.
\end{abstract}

Keywords: Gap graded concrete, M sand, Titanium dioxide, compressive strength, permeability

\section{INTRODUCTION}

\subsection{GENERAL}

A larger amount of rainwater ends up falling on impervious surfaces such as parking lots, driveways, sidewalks, and streets rather than soaking into the soil. This creates an imbalance in the natural ecosystem and leads to a host of problems including erosion, floods, ground water level depletion and pollution of rivers, lakes, and coastal waters as rainwater rushing across pavement surfaces picks up everything from oil and grease spills to de-icing Salts and chemical fertilizers. Conventional normal weight Portland cement concrete is generally used for pavement construction. The impervious nature of the concrete pavements contributes to the increased water runoff into the drainage system, over-burdening the infrastructure and causing excessive flooding in built-up areas. Thus Gap graded concrete can play a vital role in filtration and rain water harvesting due to its porosity. This type of concrete has become significantly popular as a sustainable application during recent decades due to its potential contribution in solving environmental issues.

\subsection{GAP GRADED CONCRETE}

The term "Gap graded concrete" typically describes a nearzero-slump, open- graded material consisting of Portland cement, coarse aggregate, little or no fine aggregate, admixtures, and water. It is such a concrete that has high porosity and allows draining freely unlike dense, high strength concrete. Its applications are therefore in conditions where water from precipitation or other sources needs to be drained. The high porosity is achieved by the absence or very low content of fine aggregates. Gap graded concrete is also known as no-fines concrete, gap graded concrete or porous concrete. It essentially consists of cement, coarse aggregate, water and little or no fine aggregate. In normal concrete, the fine aggregates typically fill in the voids between coarse aggregates. But in Gap graded concrete fine aggregate is non-existent or present in very small amounts. Moreover, there is globally considerable research is being done on Gap graded concrete that can be used for concrete flatwork applications. Typically Gap graded concrete has water to cementitious materials ratio (w/cm) of 0.28 to 0.40 with a void content of 18 to $35 \%$.Gap graded concrete is used in parking areas, areas with light traffic, residential streets, pedestrian walkways, and greenhouses.

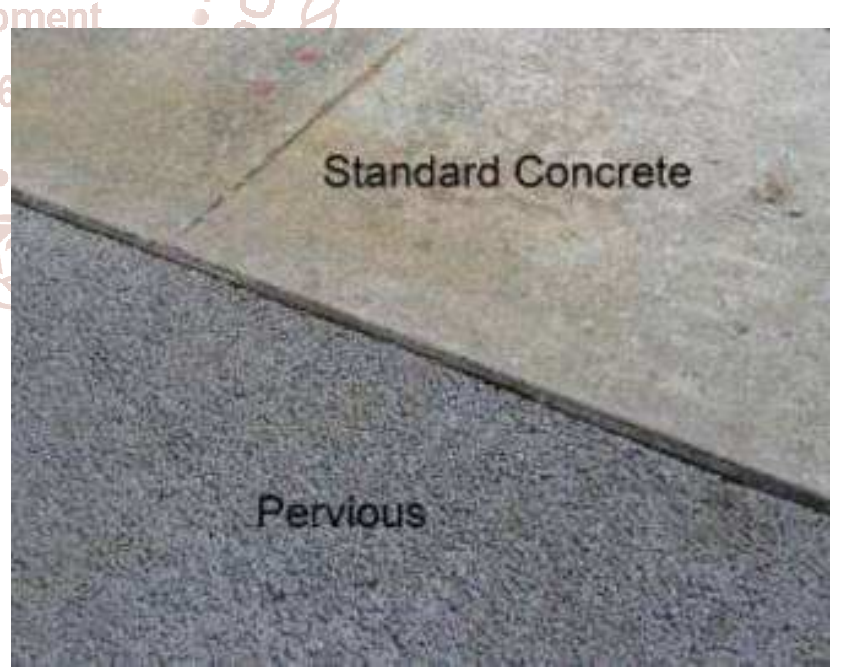

Figure1.1 Samples of Standard Concrete \& Gap graded Concrete

It is an important application for sustainable construction and is one of the techniques used for ground water recharge. Gap graded concrete naturally filters water from rainfall or storm and can reduce pollutant loads entering into streams, ponds and rivers. So in this way it helps in ground water recharge. It also reduces the bad impact of urbanization on trees. A Gap graded concrete ground surface allows the transfer of water and air to root systems allowing trees to flourish. 


\subsection{APPLICATION OF GAP GRADED CONCRETE}

This type of Gap graded concrete pavement can be used for pavements on Light weight vehicles are passing, driveways, sidewalks, footpaths, parking place for light motor vehicles, Tennis courts, Tree grate, Swimming pool decks, garden walkway, and Pavement edge drains. This may be used as inverted filter in hydraulic structures at downstream side.

\subsection{ADVANTAGES}

D Decreasing flooding possibilities, especially in urban areas

$>$ Recharging the groundwater level

$>$ Reducing puddles on the road

$>$ Improving water quality through percolation

$>$ Heat absorption

$>$ Sound absorption

$>$ Supporting vegetation growth

$>$ Dust free environment

\subsection{DISADVANTAGES}

$>$ Low strength due to high porosity

$>$ High maintenance requirement

$>$ Limited use as a load bearing unit due to its low strength

$>$ Strength is less as compared to impervious concrete pavement

\subsection{MANUFACTURED SAND}

Manufactured Sand is sand produced from crushing of granite stones in required grading to be used for construction purposes as a replacement for river sand.

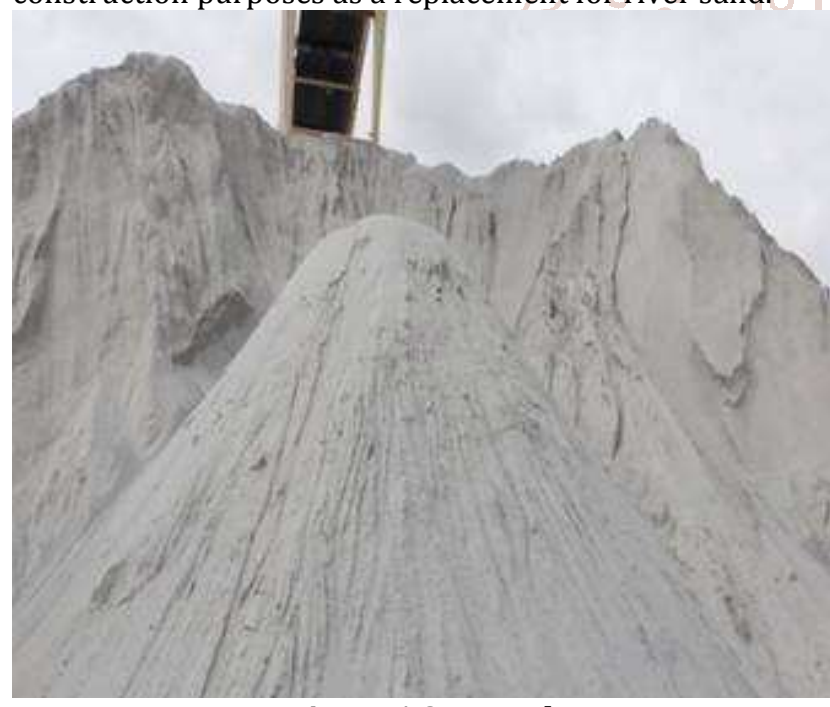

Figure 1.2 M sand

1.7 Properties of Manufactured Sand used for construction are:

\subsubsection{Higher Strength of concrete:}

The manufactured sand has required gradation of fines, physical properties such as shape, smooth surface textures and consistency which makes it the best sand suitable for construction. These physical properties of sand provides greater strength to the concrete by reducing segregation, bleeding, honeycombing, voids and capillary. Thus required grade of sand for the given purpose helps the concrete fill voids between coarse aggregates and makes concrete more compact and dense, thus increasing the strength of concrete.

\subsubsection{Durability of concrete:}

Since manufactured sand (M-Sand) is processed from selected quality of granite, it has the balanced physical and chemical properties for construction of concrete structures. This property of M-Sand helps the concrete structures withstand extreme environmental conditions and prevents the corrosion of reinforcement steel by reducing permeability, moisture ingress, increasing the durability of concrete structures.

\subsubsection{Workability of concrete:}

Size, shape, texture play an important role in workability of concrete. With more surface area of sand, the demand for cement and water increases to bond the sand with coarse aggregates.

The control over these physical properties of manufacturing sand make the concrete require less amount of water and provide higher workable concrete. The less use of water also helps in increasing the strength of concrete, less effort for mixing and placement of concrete, and thus increases productivity of construction activities at site.

\subsubsection{Less Construction Defects:}

Construction defects during placement and post-concreting such as segregation, bleeding, honeycombing, voids and capillarity in concrete gets reduced by the use of M-Sand as it has optimum initial and final setting time as well as excellent fineness.

\subsubsection{Economy:}

As discussed above, since usage of M-Sand has increased durability, higher strength, and reduction in segregation, permeability, increased workability, decreased postconcrete defects, it proves to be economical as a construction material replacing river sand. It can also save transportation cost of river sand in many cases.

\subsubsection{Eco-Friendly:}

Usage of manufactured sand prevents dredging of river beds to get river sand which may lead to environmental disaster like ground water depletion, water scarcity, threat to the safety of bridges, dams etc. to make M-Sands more ecofriendly than river sand.

\subsection{Photocatalyst Titanium Dioxide}

Photocatalysis is the acceleration of a photoreaction in the presence of a catalyst. It is a technology that could help mitigate air pollution and ultraviolet rays. Photocatalytic components use energy from sunlight (or other ultraviolet light sources) and convert into harmless substances. These products reduce NOx, SOx, smoke, bacteria etc. from the atmosphere and also serve as self-clean material. Photocatalysis employs semiconductors such as strontium titanate (SrTiO3), titanium dioxide (TiO2), Zinc Oxide ( $\mathrm{ZnO}$ ), Zinc Sulphide (ZnS) and Cadmium sulphide (CdS) as a photocatalyst. Amongst which $\mathrm{TiO} 2$ possesses the highest photocatalytic activity and is one of the most widely used semiconductors for photocatalysis. The photocatalyst, titanium dioxide is a naturally occurring compound that can decompose gaseous pollutants with the presence of sunlight. Titanium dioxide also known as titanium oxide or titania is the naturally occurring oxide of titanium, chemical formula Ti02. It is mainly sourced from Ilmenite ore.This is the most widespread form of titanium dioxide-bearing ore around the world. When used as a pigment, it is called titanium white. TiO2 is a white, highly stable and unreactive metal oxide, present in nature in three different polymorphs: anatase, rutile and brookite. Rutile and anatase have been used since 
the 1920 "s in many different industrial fields as white pigments due to their high pigmentation power and high stability whereas brookite is not commonly used. The beneficial effects of the photocatalytic activity of titanium dioxide have been applied to various materials. The most important application areas are paints and varnishes as well as paper and plastics, which account for about $80 \%$ of the world's titanium dioxide consumption. Other pigment applications such as printing inks, fibers, rubber, cosmetic products and foodstuffs account for another $8 \%$. The rest is used in other applications such as production of technical pure titanium, glass and glass ceramics, electrical ceramics, catalysts, electric conductors and chemical intermediates. In the food industry, TiO2 is also widely used as a colorant.

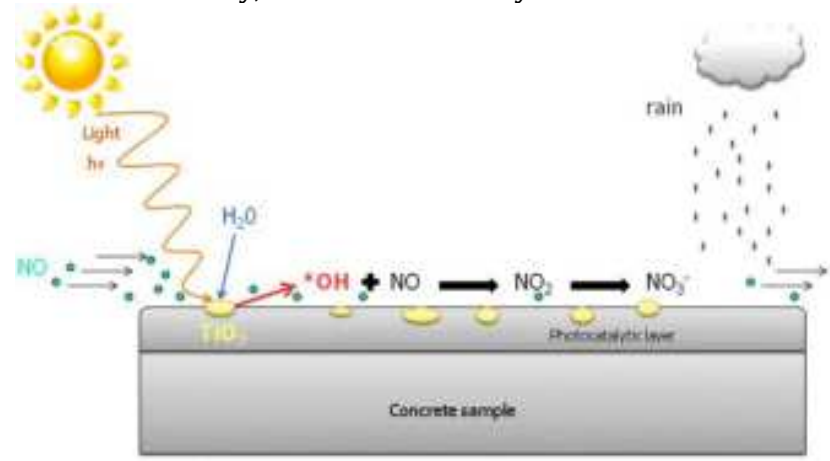

Fig 1.3 Photocatalysis

\subsection{Sustainable Application}

The use of Gap graded concrete as pavement material with little or almost no fine aggregate and just enough cementations paste to bind together the coarse aggregate has been recognized as Best Management Practice (BMP) by the US Environment Protection Agency (EPA). By allowing the storm water to percolate into the ground surface, Gap graded concrete allows the recharge of groundwater table in addition to reducing the amount of runoff. The lower amount of runoff now requires sewers of smaller capacity and reduces the need or size of retention basins. Gap graded concrete also acts as a filtration device and reduces the pollutant load entering the ponds and rivers. An additional benefit of Gap graded concrete is to provide air and water to the root system of trees, allowing them to grow well even in urban areas.

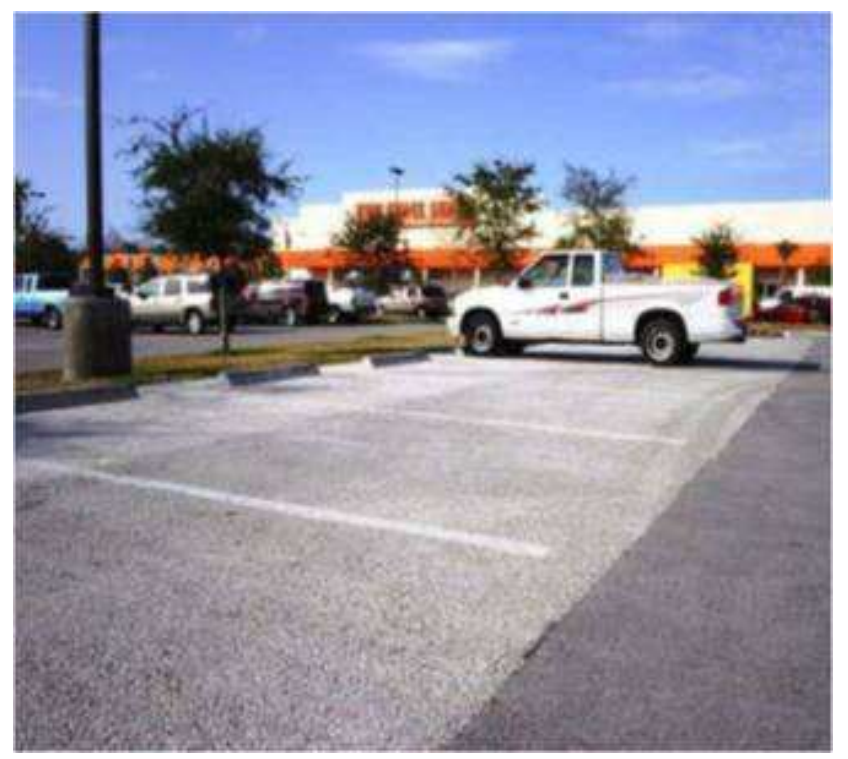

Fig 1.4 Gap graded concrete parking

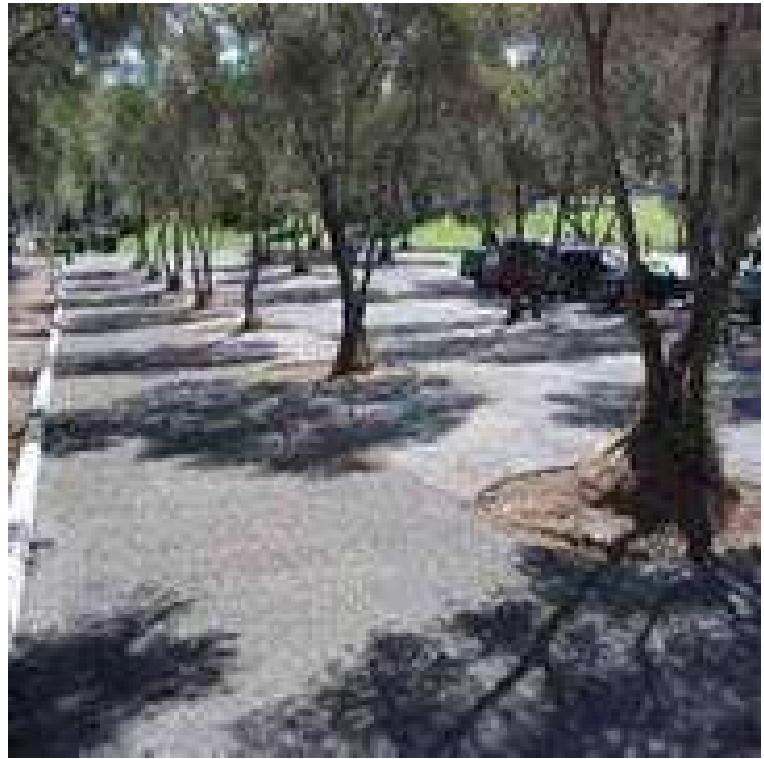

Fig 1.5 Gap graded concrete pavements

Titanium dioxide also has many uses and environment benefits. Due to its high stability it can be used with other materials efficiently.

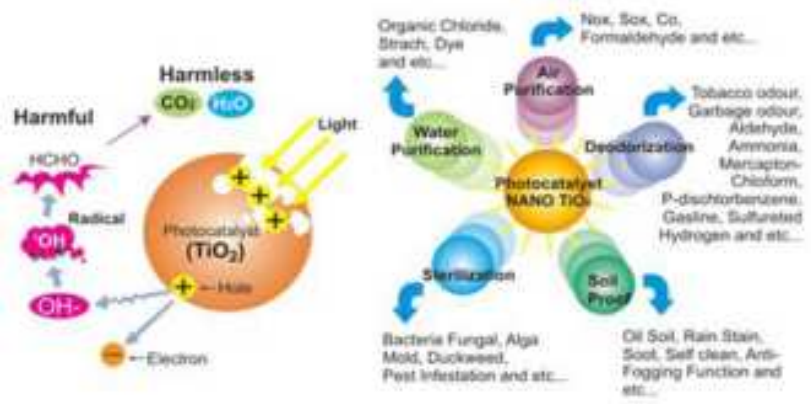

Fig 1.6 Environment benefits of titanium dioxide

The development of innovative sustainable technologies for the environmental improvement is an absolute need. Photocatalytic Gap graded concrete can represent a significant contribution in this path and can be widely implemented in the construction industry vide Gap graded concrete pavements, roadways and walkthroughs. Photocatalytic cement based products are increasingly used worldwide in the construction sector. Gap graded concrete with titanium dioxide,possessing high water draining properties and sound-absorbing properties combined with photocatalytic effect of titanium dioxide, is one of the most promising concrete solutions for removal of air and water pollutants and water drainage and runoff problems in urban cities.

\section{PERVIOUS CONCRETE \\ $+$}

\section{TITANIUM} DIOXIDE

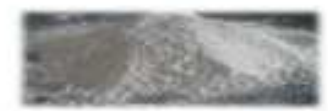

ECOSUSTAINABLE

PERVIOUS CONCRETE

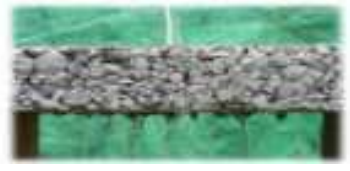

Fig 1.7 Concept of Eco-sustainable Gap graded concrete 
Sustainable engineering practice can be obtained with this no-fine concrete, whose aggregate grading allows adequate drainage of recyclable rainwater, whose maintenance works are strongly reduced with significantly increased durability by application of photocatalyst titanium dioxide. Thus, Gap graded concrete with titanium dioxide can be utilized as an efficient sustainable application.

\subsection{MAINTENANCE}

Over time, sand, dirt, vegetation, and other de $\neg$ bris can collect in Gap graded concrete's voids and reduce its porosity, which can negatively affect the functionality of the system. Thus, periodic maintenance may be needed to remove sur $\neg$ face debris and restore infiltration capacity. Two common maintenance methods are pressure washing and power vacuuming (ACI 2010).

\subsection{AIM OF THE STUDY}

The aim of this study is to evaluate the structural performance of Gap graded concrete in civil engineering construction. To achieve this, the effects of varying the aggregate size on the porosity, compressive strength and specific gravity of Gap graded concrete were studied. The study covers the simple use of Gap graded concrete as pavement material in the construction of pedestrian walkways and parking lots.

\subsection{OBJECTIVE AND SCOPE}

The objective of the present study was to investigate available laboratory test methods for evaluating abrasion and raveling resistance of PCPC. The tests considered the fresh concrete and harden concrete. Fresh concrete is considered the slump cone test. The harden concrete is considered to be compressive strength, porosity, infiltration and permeability test.
In recent times many studies have been carried out on no fines concrete. The objective of the present study is to check the performance of no fines concrete on various sizes of aggregates. Concrete is the most important material for construction purposes and cement is the most expensive ingredient in it. The name of no fines concrete itself explains that the fine aggregate has been omitted in this kind of concrete. Due to the absence of fine aggregate in no fines concrete, there is a high percentage of void space which results in high permeability. The unit weight, drying shrinkage and hydrostatic pressure for no fines concrete is less compared to conventional concrete. Due to the less cement content in no fines concrete, the cost of the overall project reduces. No fines concrete also helps in the reduction of urban heat island effect due to its light color. In this project cubes of $150 \mathrm{mmxl} 50 \mathrm{~mm}$ x $150 \mathrm{~mm}$ size are caste with two categories of $(10 \mathrm{~mm} \& 20 \mathrm{~mm})$ coarse aggregates. The cubes are tested and their corresponding Compressive strengths and densities are noted.

\section{TESTING OF MATERIAL}

Introduction related your research work Introduction related your research work Introduction related your research work Introduction related your research work Introduction related your research work Introduction related your research work Introduction related your research work Introduction related your research work Introduction related your research work Introduction related your research work

\subsection{Cement}

Ordinary Portland cement was used for the project work. The cement was tested as per IS codal provisions.

Following are the observations

Table 2.1 Summary of test results of Cement.

\begin{tabular}{|c|c|c|c|c|}
\hline $\begin{array}{l}\text { Sr. } \\
\text { no }\end{array}$ & Properties & $\begin{array}{c}\text { Result } \\
\text { Obtained }\end{array}$ & $\begin{array}{l}\text { Standard Values as per } \\
\text { Indian Standards }\end{array}$ & Codal Provision \\
\hline 1 & Standard Consistency & $33 \%$ & & $\begin{array}{c}\text { IS } 269: 1989 \text { Clause No. } 11.3 \\
\text { IS } 4031 \text { (Part4): } 1988 \text { Clause } 5.1\end{array}$ \\
\hline 2 & Initial Setting Time & $45 \mathrm{~min}$ & $\begin{array}{l}\text { Not be less than } 30 \\
\text { minutes }\end{array}$ & $\begin{array}{c}\text { IS 269:1989 Clause No. } 5.2 \\
\text { and } 6.3\end{array}$ \\
\hline 3 & Final Setting Time & $185 \mathrm{~min}$ & $\begin{array}{l}\text { Not be greater than } 600 \\
\text { minutes }\end{array}$ & $\begin{array}{c}\text { IS 269:1989 Clause No. } 5.3 \\
\text { and } 6.3\end{array}$ \\
\hline 4 & Specific gravity & 3.13 & - & - \\
\hline
\end{tabular}

\subsection{Fine Aggregates}

Natural fine aggregates which were locally available were used in the project work. Following are the result obtained after testing of fine aggregates.

Table 2.2 Summary on Physical Properties of fine aggregates.

\begin{tabular}{|c|c|c|}
\hline Sr. No. & Properties & Result Obtained \\
\hline 1 & Type & Natural \\
\hline 2 & Particle Shape & Rounded \\
\hline 3 & Grading Zone & Zone-II \\
\hline 4 & Fineness Modulus & 2.6 \\
\hline 5 & Specific Gravity & 2.81 \\
\hline
\end{tabular}

\subsection{Coarse Aggregates}

Natural coarse aggregates which were locally available were used in the project work. Following are the result obtained after testing of coarse aggregates.
Table 2.3 Summary on Physical Properties of Coarse Aggregates

\begin{tabular}{|c|c|c|}
\hline Sr. No & Properties & Result obtained \\
\hline 1 & Type & Natural \\
\hline 2 & Specific Gravity & 2.66 \\
\hline 3 & Particle Shape & Angular \\
\hline 4 & Fineness Modulus & 6.27 \\
\hline 5 & Water abservation & $0.5 \%$ \\
\hline 6 & Surface Texture & Rough \\
\hline
\end{tabular}

\subsection{Titanium Dioxide}

Titanium dioxide was provided by CSIR NEERI, the physical and chemical properties of titanium dioxide are as follows 
Table 2.4 Physical and Chemical Properties Titanium dioxide

\begin{tabular}{|c|c|c|c|}
\hline Sr. No & Properties & Unit & Value \\
\hline 1 & Specific surface area & $\mathrm{m} 2 / \mathrm{g}$ & $50 \pm 15$ \\
\hline 2 & $\begin{array}{l}\text { Average primary particle } \\
\text { size }\end{array}$ & $\mathrm{Nm}$ & 21 \\
\hline 3 & $\begin{array}{c}\text { Moisture } \\
\left(2 \mathrm{hrs} \text { at } 105^{\circ} \mathrm{C}\right)\end{array}$ & Wt.\% & 1.5 \\
\hline 4 & $\begin{array}{c}\text { Ignition loss } \\
\left(2 \mathrm{hrs} \text { at } 1000^{\circ} \mathrm{c}\right)\end{array}$ & Wt.\% & 2.0 \\
\hline 5 & pH ( in 4\% dispersion) & Wt.\% & 4.5 \\
\hline 6 & TiO2 & Wt.\% & 99.50 \\
\hline 7 & Al2O3 & Wt.\% & 0.300 \\
\hline 8 & $\mathrm{SiO} 2$ & Wt.\% & 0.200 \\
\hline 9 & $\mathrm{Fe} 203$ & Wt.\% & 0.010 \\
\hline 10 & Sieve residue $(45 \mu \mathrm{m})$ & Wt.\% & 0.0500 \\
\hline 11 & Density & $\mathrm{Kg} / \mathrm{m} 3$ & 130 \\
\hline 12 & $\mathrm{pH}$ & Wt.\% & 4.5 \\
\hline
\end{tabular}

\section{MIX PROPORTION}

There are no codal provisions relevant to the mix design of pervious concrete in Indian standards or other standards of the world. American standards such as ACI 522R only deals with the different applications, material specifications and strength properties of pervious concrete. There is no specific reference of mix design of pervious concrete in these codes. Most of the pervious concrete mix depends upon the requirement and specifications and are accomplished by adopting trial mixes. Although pervious concrete contains the same basic ingredients as the conventional concrete, the proportions of the ingredients can vary. One major difference is the requirement of increased void content within the pervious concrete. The amount of void space and porosity is directly correlated to the permeability of the pervious con crete. More the porosity and voids more will be the water permeability but the compressive strength will be less.

\subsection{Experimental Mix}

Experimental mixes include pervious concrete trial mix having optimum compressive strength and partial replacement of cement with titanium dioxide was adopted. Following are the experimental mix adopted for the investigation.

\begin{tabular}{|c|c|c|c|c|}
\hline Sr. No & Mix type \& No & Coarse aggregates & Fine aggregates & Titanium Dioxide \\
\hline 1 & Trial 1 & $20 \mathrm{~mm}(50 \%)+10 \mathrm{~mm}(50 \%)$ & $4 \%$ by wt. of CA & $2.5 \%$ by weight of Cement \\
\hline 2 & Trial 2 & $20 \mathrm{~mm}(50 \%)+10 \mathrm{~mm}(50 \%)$ & $4 \%$ by wt. of CA & $5 \%$ by weight of Cement \\
\hline 3 & Trial 3 & $20 \mathrm{~mm}(50 \%)+10 \mathrm{~mm}(50 \%)$ & $4 \%$ by wt. of CA & $7.5 \%$ by weight of Cement \\
\hline 4 & Trial 4 & $20 \mathrm{~mm}(50 \%)+10 \mathrm{~mm}(50 \%)$ & $4 \%$ by wt. of CA & $10 \%$ by weight of Cement \\
\hline
\end{tabular}

\section{TEST RESULTS AND INTERPRETATION Internationa Summary of Results}

4.1 Interpretation of compressive test results for in 1. Highest compressive strength (28days) for pervious Experimental mix concrete is observed as $13.66 \mathrm{~N} / \mathrm{mm} 2$ for Experimental Mix-2 having 5 percent replacement of cement with

28 days compressive strength $\mathrm{N} / \mathrm{mm} 2$
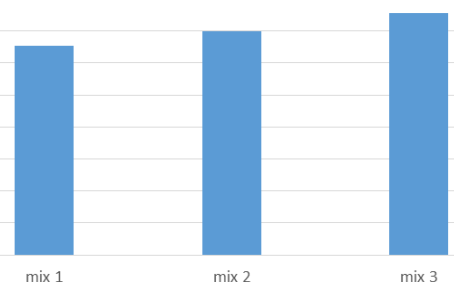

- 28 days compressive strength $\mathrm{N} / \mathrm{mm} 2$

Compressive strength for $\mathbf{2 8}$ days

Permeability test for 28 days $\mathrm{mm} / \mathrm{s}$
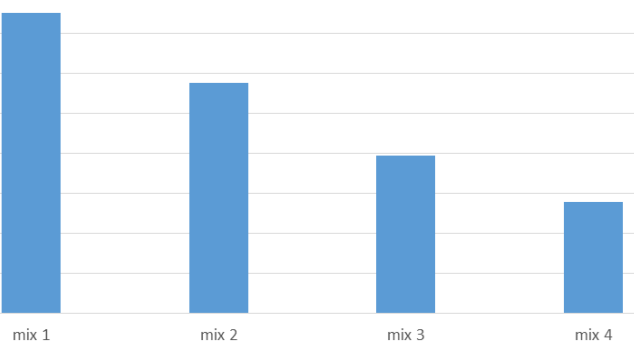

Inermeability test for 28 days $\mathrm{mm} / \mathrm{s}$

Permeability test for $\mathbf{2 8}$ days titanium dioxide. The water permeability for this mix calculated is $15.4 \mathrm{~mm} / \mathrm{sec}$.

2. Addition of Titanium dioxide up to 2.5percent as partial replacement of cement in pervious concrete resulted in the percentage increase of 13.13percent in the compressive strength.

3. Addition of Titanium dioxide up to 5percent as partial eplacement of cement in pervious concrete resulted in the percentage increase of 23.73percent in the compressive strength.

4. Partial replacement of cement with titanium dioxide up to 10percent resulted in percentage decrease of 8percent in compressive strength when compared to the pervious concrete with 5percent addition of titanium dioxide.

5. $5.15 \%$ replacement of $\mathrm{M}$ sand is acceptable for better strength and permeability

\section{CONCLUSION}

1. Compressive strength of pervious concrete increases and water permeability decreases with the increase of fine aggregate in pervious concrete.

2. Pervious concrete with maximum compressive strength can be obtained by combination of $20 \mathrm{~mm}$ and $10 \mathrm{~mm}$ aggregates or with single size $10 \mathrm{~mm}$ aggregates along with use of fine aggregates in small quantity.

3. Water permeability is one of the important characteristics of pervious concrete and therefore the fine aggregate shall be used in pervious concrete within range of 2 to 4 percent by weight of coarse aggregates. 
International Journal of Trend in Scientific Research and Development (IJTSRD) @ www.ijtsrd.com eISSN: 2456-6470

4. 4. Addition of titanium dioxide as partial replacement to cement improves the compressive strength and splitting tensile strength of pervious concrete

5. 5. Partial replacement of cement with titanium dioxide in the pervious concrete has no considerable adverse effect on water permeability of pervious concrete.

\section{REFERENCES}

[1] Biji. U.I ${ }^{1}$, M. Rajeswari ${ }^{2}$, Dhaarani.K. $\mathrm{K}^{3}$, Karthikai Raja. $\mathrm{k}$ (2016) "Gap graded concrete for pavement: International journal of Emerging Technology and Advanced Engineering (IJETAE)-Vol 6, Issue9.

[2] Darshan. S Shah ${ }^{1}$, Prof. Jayeshkumar Pitroda ${ }^{2}$ Prof. J.J.Bhavasar ${ }^{3}$ (2013) "Gap graded Concrete: New Era For Rural Road Pavement, International Journal of Engineering Trends and Technology (IJETT)"Vol4 issue 8.

[3] Joaovirgilio merighi ${ }^{1}$, RITA moulrfortes ${ }^{2}$, and alex banderira $^{3}$ previous concrete $^{1}$ : for use on the airport runways, Department of Civil Engineering, 2012, Issue.
[4] Rezene madhi, Ph.D ${ }^{1}$, Mr.Wasikhan ${ }^{2}$ previous concrete: for an urban area, Department of Civil Engineering Howord university. Vol3. Issue12 (IJOFERDT).

[5] M.Uma mageswari; and V. L Narasimba previous concrete: for the pavement applications proceedingsocial and behavioural sciences.

[6] N. Ghafoori1, S. Dutta2, „Building and non-pavement applications of no-fines concrete", Journal of Materials in Civil Engineering, 1995: 7(4): pg. 286-289

[7] P. D. Tennis1, M. L. Leming2 and D. J. Akers3, „Gap graded concrete pavements", National Ready Mixed Concrete Association, Maryland, 2004

[8] Tejas M. Joshi, „Effect of sand content in permeability of Gap graded concrete", Institute of technology, Nirma University, Ahmedabad, Gujarat, India, 2011.

[9] Thilak Jayathunga1, Ranjith Dissanayake2, „Gap graded concrete - a sustainable choice in civil engineering and construction", Head of Innovation and Applications, Holcim (Lanka) Limited, Department of Civil Engineering, University of Peradeniya, Sri Lanka,2013.

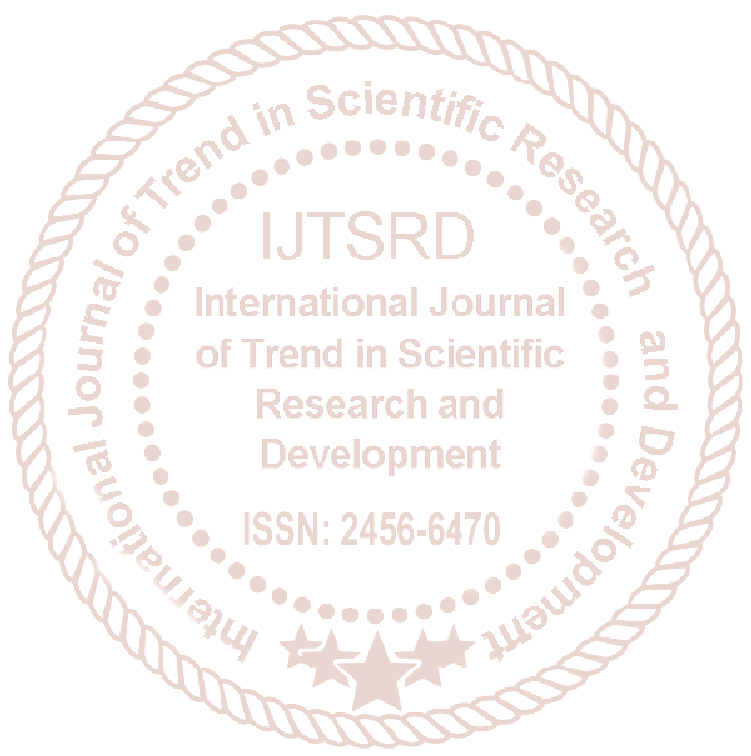

